\title{
Greek Teachers' Perceptions on the Effective Strategies and Interventions for Addressing Children with Depression in School Context
}

\author{
Eleni Nikolaou, ${ }^{1, *}$, Loukas Moustakas ${ }^{1}$, Georgios Markogiannakis ${ }^{2}$ \\ ${ }^{1}$ Department of Preschool Education Sciences and Educational Design, University of the Aegean, Rhodes, Greece \\ ${ }^{2}$ Independent Researcher, Rhodes, Greece

\section{Email address:} \\ enikolaou@rhodes.aegean.gr(E.Nikolaou),lmoustakas@rhodes.aegean.gr(L. Moustakas), gmarkog@sch.gr(G. Markogiannakis) \\ ${ }^{*}$ Corresponding author
}

\section{To cite this article:}

Eleni Nikolaou, Loukas Moustakas, Georgios Markogiannakis. Greek Teachers' Perceptions on the Effective Strategies and Interventions for Addressing Children with Depression in School Context. Science Journal of Education. Vol. 5, No. 4, 2017, pp. 185-191. doi: 10.11648/j.sjedu.20170504.20

Received: May 21, 2017; Accepted: June 23, 2017; Published: July 26, 2017

\begin{abstract}
The aim of the present research is to explore teachers' perceptions about the effective strategies for addressing children's depression in school context, as well as the appropriate preventive counseling interventions within school context. The sample of this research study was 116 teachers of primary education. Data were collected by a questionnaire that was based on previous research. The findings show that teachers regard that supporting children, a positive interpersonal relationship with these children, a positive climate in the classroom, cooperation with parents and mental health professionals are among the effective strategies. In relation to the appropriate preventive counseling interventions, they argue that the implementation of socio-emotional programs by teachers in cooperation with mental health professionals, as well as the delivery of mental health prevention programs to all children by mental health specialists are effective strategies. Research findings may be utilized for designing teacher training and professional development programs aiming at supporting children with depression and mental health promotion.
\end{abstract}

Keywords: Teacher Perceptions, Depression, School, Strategies, Intervention

\section{Introduction}

Depression is one of the most common mood disorders with adverse effects on the development of children. Children with depression have decreased school performance, disturbed relationships, suicidal thoughts, and high rates of alcohol and substance use [1]. $50 \%$ of children who meet the criteria for major depression will continue to have depressive episodes in adulthood [2]. Children who have subclinical levels of depressive symptoms at an early age are more likely to have major depressive episodes in adulthood [3].

The significant impacts of depression on child development make it necessary to explore the perceptions of teachers on the effective strategies for addressing depression in children, as their perceptions influence their behavior and responses towards children. The way teachers deal with behavioral problems has an impact on the extent to which these behavioral problems deteriorate [4]. In addition, a limited number of studies have studied teacher perceptions for behavioral problems and, in particular, internalization problems.

The older children diagnosed with depression display lack of pleasure, feelings of helplessness, weight loss, social withdrawal, psychomotor retardation, and suicidal ideation at higher levels than younger children [5].Younger children are more likely to express physical complaints and experience social withdrawal [6]. Moreover, psychomotor anxiety can be expressed as irritability or through the temper tantrums of younger children [7]. Many children have subclinical levels of depression that do not meet the criteria for the duration and severity of symptoms. However, these subclinical events have an impact on child functioning, such as major depression [3]. Children with depression are a heterogeneous group characterized by a wide range of symptoms. They 
differ in the profile of clinical symptoms, the severity and course of the disorder.

Depression is characterized by heterogeneity and it is the result of the interaction of biological (genetic, neurobiological), family (e.g. mother depression), and individual (e.g. socio-emotional) factors [8].

Protective factors that prevent depressive symptoms are high levels of intelligence, problem-solving skills and good social skills [9]. Furthermore, social support, peer relationships, teacher support [10], a warm and stable relationship with at least one parent [11] are considered protective factors.

\section{Strategies for Dealing with Children with Depression at School}

Prevention of mental disorders and intervention positively affect academic achievement, as children with better developed social, emotional and behavioral skills have better academic outcomes [12].

Huberty argues that the development of a collaborative relationship with students displaying depressive mood and consultation with school mental health personnel (school psychologists, social workers) are essential strategies for addressing childhood depression [13]. The discussion with students about their feelings satisfies their need for shaping qualitative relationships with caring adults and listening attentively to their concerns.

Collaborative relationships between family, school, and community mental health services are critical in fostering children's psychosocial adjustment. Parents and teachers can discuss about children's difficulties, needs and collaboratively devise ways of helping students suffering from depression. Joint meetings can contribute to receiving students the appropriate services [14].

School mental health personnel can connect families to local community mental health services, make referrals to outside mental health services for additional support and develop partnerships with community agencies. Desrochers and Houck point out that family-school-community collaboration is of utmost importance [15].

Kidger, Araya, Donovan, \& Gunnell assert that teacher support enhances school connectedness and is associated with emotional health [16]. Close relationships with teachers are linked to fewer emotional problems. The sense of belonging to school as well as other characteristics of school climate, such as the quality of relationships within the school context, promote emotional development and well-being [17]. Teacher-child relationships, peer relationships and peer support impact on psychological adjustment.

\section{Prevention Interventions for Depression}

School is considered the ideal venue for the implementation of mental health prevention programs.
Teachers are able to observe and detect signs of mental health problems. Preventive interventions are classified into three categories: universal, selective and indicated. Universal interventions are targeted at the whole population. Selective interventions target individuals who are considered to be at increased risk of experiencing a particular mental disorder (for example, children with parent depression). Appropriate targets for indicated interventions are those who already have early signs of symptoms of a mental disorder, but who do not yet meet the diagnostic criteria [18].

The socio-emotional learning programs are universal interventions. They promote emotional development, well-being, and enhance protective factors [19]. These programs which comprise the skills of recognizing and managing emotions, establishing positive relationships, responsible decision making and handling interpersonal relations constructively, contribute to positive mental health and resilience [20].

Interventions are also targeted at children who are not diagnosed but are considered to be at increased risk of developing depression. These children have negative life events, demographic characteristics associated with increased risk of depression, and other variables that have been found to increase the risk of developing depression [21].

The Penn Resiliency Program has been evaluated as a universal, selective and indicated intervention and most studies support its effectiveness [22]. It has had positive results in reducing depressive emotions, both as a universal intervention and as indicated[23]. This intervention resulted in a reduction in depressive symptoms, which lasted from six months to two years [24]. Within the framework of this program, which was also implemented in schools, it was intended to teach that negative thoughts affect behavior and feelings. Participants learned to recognize their positive thoughts and replace them using cognitive restructuring techniques [25].

An example of a preventive selective intervention is Beardslee's intervention, which implemented a psychoeducational preventive intervention in 100 families with at least one parent with a diagnosis of emotional disturbance and their 8-15 age-old children who were not diagnosed with depression [26]. The intervention was carried out by trained staff who had regular supervision. The sessions included separate sessions with parents and children, as well as family meetings. Parents were given psycho-educational material about emotional disturbances for risk factors and the development of psychological resilience. The aim was to reduce risk factors and develop protective factors through changing parents' attitudes and increasing their knowledge of the etiology of depression. The intervention had brought about positive changes to both parents and children and reduced the symptoms of internalization. Calear and Christensen argue that targeted interventions lead to a greater reduction in depressive symptoms than universal or selective interventions [27]. 


\section{Previous Research Studies}

There has not been found research studies in the relevant literature review investigating teachers' perceptions regarding children with depression. However, there has been conducted studies for children with emotional and behavioral difficulties or for children with mental health problems in general.

According to Poulou and Norwich, the strategies that the teachers of the sample considered the most effective for managing children with emotional and behavioral disorders were gaining children's confidence, involving children in classroom activities and expressing their personal interest as well as supporting them [28]. Cooperation with mental health specialists and cooperation with parents were also perceived as effective strategies. Teacher collaboration with the school principal was assessed as less effective. Moreover, the appointment of special educators, qualified staff, specialists for visiting schools were evaluated as effective strategies.

Vostanis, Humphrey, Fitzgerald, Deighton, and Wolpert explored the strategies of supporting students' mental health in school context [29]. They found that listening to the children's problems, understanding and support were the most frequently used strategies by the educational personnel. Teachers in most schools encouraged children to participate in support groups. Moreover, most schools organized meetings with parents. In addition, teachers reported that they taught new skills for problem-solving and forming satisfying relationships with peers. The majority, $61 \%$ of primary schools, were focusing their efforts on all students rather than on small groups.

The strategy most often used by educational staff members was listening to children's problems, and providing understanding and general support (94\%). In most schools, students were encouraged to participate in a support group to discuss their problems. The majority of schools (94\%) offer support to the family of children in the form of organizing meetings with parents for helping find solutions or techniques that will contribute to coping with their anxieties. Among the most common approaches and strategies were the development of social and emotional skills (72.8\%). Less commonly used strategies were support and counseling $(16.7 \%)$, parent education $(20.3 \%)$, provided by mental health services for children, counseling and support for the educational staff.

Stefan, Rebega and Cosma explored preschool teachers' perceptions for children with behavior and emotional difficulties in Romania [30]. Cooperation with parents (communication with parents and parents' involvement in children's activities) was regarded as an important strategy for dealing with children with emotional and behavioral problems, as well as the discussion with children and guidance in a process of problem-solving.

The aforementioned studies point out that the discussion with these children, support, cooperation with parents and collaboration with mental health professionals as well as socio-emotional skills training and peer support are among the strategies that are identified as effective.

The above findings highlight the importance of prevention and implementation of strategies for supporting mental health of students with depression. As a result, there is the need to understand teachers' perceptions regarding the effective strategies and interventions for prevention.

\section{Methodology}

The sample of this research study consisted of 116 primary education teachers in Rhodes, Greece. $75 \%$ of the participants had a bachelor's degree, $23.3 \%$ had a master's degree and $1.7 \%$ had a doctoral degree. $35.3 \%$ of the respondents had taught 6 to ten years, 25\% had taught eleven to fifteen years, $12.9 \%$ twenty-six and above years, $7.8 \%$ twenty-one to twenty-five years and $7.8 \%$ one to five years. $34.5 \%$ of the sample had been trained in special education, $6.9 \%$ had a bachelor's degree in special education, and 5.2\% a master's degree in special education. A five-part survey instrument was developed to include demographic information and survey questions using a four-point Likert scale. The survey contained questions relating to the participants' demographic characteristics, as shown in Table 1, as well as questions pertaining to their beliefs about the effective strategies and preventive interventions within school context. A pilot study was conducted to assess the readability, clarity and comprehensiveness of the questions and it was revised based on their feedback.

Table 1. Distribution of frequencies of the demographic factors of the sample.

\begin{tabular}{lll}
\hline Gender & Frequency $\mathbf{N = 1 1 6}$ & Percent (\%) \\
\hline Male & 32 & 27.6 \\
Female & 84 & 72.4 \\
Age & & \\
$22-29$ & 25 & 21.6 \\
$30-39$ & 29 & 25.0 \\
$40-49$ & 46 & 39.7 \\
$>49$ & 16 & 13.8 \\
Specialty & & \\
Teacher & 111 & 95.7 \\
Special Ed. Teacher & 4 & 3.4 \\
\hline
\end{tabular}

\section{Results and Discussion}

Table 2 shows that $94.0 \%$ of the sample regards that the most effective strategy for addressing students' depression is "supporting children". 
Table 2. Distribution of Participants' Responses Regarding the most Effective Strategies for Children with Depression.

\begin{tabular}{|c|c|c|c|c|c|}
\hline \multicolumn{6}{|c|}{ Which of the following strategies do you regard as most effective for addressing the behaviors described in the vignette? } \\
\hline & \multicolumn{2}{|c|}{ Not at all effective } & \multicolumn{3}{|c|}{ Most Effective } \\
\hline & 1 & 2 & 3 & 4 & 5 \\
\hline Discussion with the child & $3.4 \%$ & & $12.9 \%$ & $81.0 \%$ & \\
\hline Involvement of children in peer support groups & $4.3 \%$ & & $14.7 \%$ & $78.4 \%$ & \\
\hline Social and emotional skill training & $6.0 \%$ & & $14.7 \%$ & $76.7 \%$ & \\
\hline Creation of a positive climate in the context of classroom & $3.4 \%$ & & $7.8 \%$ & $85.3 \%$ & \\
\hline Cooperation with mental health professionals & $2.6 \%$ & & $8.6 \%$ & $86.2 \%$ & \\
\hline Cooperation with the principal & $22.4 \%$ & & $25.0 \%$ & $50.0 \%$ & \\
\hline Cooperation with parents & $3.4 \%$ & & $6.9 \%$ & $87.1 \%$ & \\
\hline
\end{tabular}

The majority of the participants believe that a positive interpersonal relationship between teachers and students is an effective strategy $(88.8 \%)$ and $85 \%$ of the participants in this study consider that the positive climate in the classroom is an appropriate strategy. A high percentage of the participants value children's involvement in peer support groups (78.4\%), whereas $76.7 \%$ consider that social skills training is an effective strategy.

In addition, $87.1 \%$ of the respondents argue that cooperation with parents of children with depression is an effective strategy for tackling the issues of children diagnosed with depression. Furthermore, $86.2 \%$ of the sample considers that cooperation with mental health professionals is an appropriate strategy for addressing the issues faced by these students.

Table 3 presents the responses of the participants in relation to their perceptions about the prevention of depression. The majority believes that the implementation of socio-emotional programs in school context by teachers after they have been trained and in cooperation with mental health professionals is an effective strategy (79.3\%). Socioemotional programs within school context conducted by mental health professionals $(75 \%)$ are also identified as an effective strategy.

Table 3. Distribution of participants' responses regarding the most effective preventive intervention for children with depression.

\begin{tabular}{|c|c|c|c|c|c|}
\hline \multicolumn{6}{|c|}{ Which of the following can contribute most to the prevention of the behaviors included in the scenario? } \\
\hline & \multicolumn{3}{|c|}{ Not at all effective } & \multicolumn{2}{|c|}{ Most effective } \\
\hline & 1 & 2 & 3 & 4 & 5 \\
\hline $\begin{array}{l}\text { 1. Implementation of mental health prevention programs within school context to all children by } \\
\text { mental health professionals }\end{array}$ & $5.2 \%$ & & $14.7 \%$ & $77.6 \%$ & \\
\hline $\begin{array}{l}\text { 2. Implementation of mental health prevention programs within school context by teachers in } \\
\text { cooperation with mental health professionals }\end{array}$ & $6.0 \%$ & & $16.4 \%$ & $75.0 \%$ & \\
\hline $\begin{array}{l}\text { 3. Implementation of programs preventing mental health disorders in school context that target } \\
\text { children who exhibit signs of mental health disorders }\end{array}$ & $6.9 \%$ & & $16.4 \%$ & $74.1 \%$ & \\
\hline $\begin{array}{l}\text { 4. Implementation of socio-emotional programs within school context by mental health } \\
\text { professionals. }\end{array}$ & $6.0 \%$ & & $16.4 \%$ & $75.0 \%$ & \\
\hline $\begin{array}{l}\text { 5. Implementation of socio-emotional programs by teachers in cooperation with mental health } \\
\text { professionals }\end{array}$ & $3.4 \%$ & & $13.8 \%$ & $79.3 \%$ & \\
\hline
\end{tabular}

A high percentage of the sample argues that the implementation of universal preventive interventions of mental health problems within school context conducted by mental health specialists is an appropriate strategy $(77.6 \%)$, whereas $75 \%$ of the respondents favor the implementation of preventive interventions in school context implemented by teachers after they have been trained and in cooperation with mental health professionals. Moreover, $74.1 \%$ regard that the implementation of selective preventive interventions is more effective.

Data were tested for their normality by using the Kolmogorov-Smirnov criterion and were not found to meet the normal distribution criteria $(\mathrm{p} \leq .05)$. For this reason nonparametric criteria were used for the statistical analysis. Mann-Whitney criterion was used to check the significance of differences for the independent variable educational level, while Kruskal-Wallis was used for the independent variable working experience.
As far as the reliability is concerned, reliability test, Cronbach's A was 84.3, indicating very high levels of internal coherence of the research tool. The analysis of the questionnaire data regarding the effect of the educational level revealed the following statistical differences (MannWhitney): The participants holding a master's degree seem to regard the discussion with the child (4.68) as more effective than those holding a bachelor's degree $(4.22)$ [U $(27,84)=$ $862.000, \mathrm{p}=.016]$. The respondents holding a master's degree seem to consider the creation of a positive climate in the classroom (4.64) more effective than those holding a bachelor's degree $(4.26)[\mathrm{U}(27,84)=890.500, \mathrm{p}=.033]$. In addition, the respondents holding a master's degree seem to regard as more effective the cooperation with parents (4.79) than those holding a bachelor's degree $(4.36)$ [U $(27,84)=$ $860.000, \mathrm{p}=.011]$.

The analysis of the questionnaire data regarding the effect of working experience on the results revealed the following 
statistical differences (Kruskal-Wallis): The respondents with working experience from 21 to 25 years seem to consider less effective (3.56) the creation of a positive climate within the classroom context, than a) those having more than 26 years of experience (4.60) b) those with 6 to 10 years of experience (4.46) and c) 11 to 15 years of experience (4.43), [H (5) = $11.693, \mathrm{p}=.039$ ], Post Hoc Tukey HSD sig. Furthermore, the respondents with 21 to 25 years of working experience seem to consider less effective (3.78) the implementation of socioemotional programs for students conducted by mental health professionals than the respondents having 11 to 15 years of experience (4.38), [H (5) $=11.328, \mathrm{p}=.045]$, Post Hoc Tukey HSD sig. Moreover, the participants with working experience from 21 to 25 years seem to regard as more effective (4.25) the implementation of socio-emotional programs for children by their teachers after training and in collaboration with mental health specialists than those having experience more than 26 years (3.93), $[\mathrm{H}(5)=11.066$, p $=.050]$, Post Hoc Tukey HSD sig.

The above data support previous findings that indicate that the expression of teacher's interest and support, the cooperation with parents and mental health specialists are among the strategies that are regarded effective for children with emotional and behavioural difficulties by teachers. [28]. These findings also add to the relevant literature arguing that listening to children's problems, understanding and support as well as meetings with parents and children's participation in support groups are among the strategies used in schools for enhancing students' mental health [29]. Moreover, Stefan et al have found that cooperation with parents and discussion with the child are considered important strategies by preschool teachers in Romania for children with emotional and behavioural difficulties [30].

The teacher's ability to listen to students' feelings and thoughts and to support them has been shown to affect pupils' attention in learning [31]. Teachers can promote the social and emotional competence of students, self-confidence and resilience through the development of relationships that are distinguished by warmth and responsiveness to pupils' needs [32]. Supportive teacher-student relationships are important, because positive social interactions create an environment that facilitates the emergence of positive behaviors within the classroom [33]. Positive parent-teacher relationships characterized by warmth and low levels of conflict are linked to social competence and adaptation to school [34]. All the above factors create an environment in which social and emotional competence can be cultivated [35]. Research findings cannot be generalized to the general population. Further research employing larger and more representative samples could shed more light on the investigated variables.

\section{Conclusions}

The responses of the participants in this research study indicate that the most effective strategies for addressing depression in children in school context are among others support, discussion with these children, the development of a positive interpersonal relationship with them, a positive climate in the classroom, cooperation with parents and mental health professionals. A lower percentage of teachers regard the cooperation with principals as an effective strategy.

The majority of the participants support the implementation of socio-emotional programs by teachers after training and in cooperation with mental health professionals. The implementation of universal preventive interventions within school context by mental health specialists is also regarded important. Simultaneously, they value universal preventive interventions implemented by teachers and selective interventions within school context.

It is crucial that teachers play a significant role in children's mental health. Research data show that teachers agree that they should participate in covering the mental health needs of students [36]. Simultaneously, it is more likely that families will participate in children's mental health treatment in school context. The role of educators in promoting students' mental health requires teacher training [37]. Detecting signs of depression and addressing depression and mental health issues within school context should be an essential part of teacher training. Recognizing and understanding mental health issues in children should be included in teachers' professional development. Teacher education and professional development will contribute to the effective implementation of preventive interventions and strategies of addressing mental health issues. In addition, teachers will be able to work effectively with students with mental health problems and support the socio-emotional and academic development of these students.

\section{References}

[1] Birmaher, B., Ryan, N. D., Brent, D. A., Kaufman, J., Dahl, R. E., Perel, J., \& Nelson, B. (1996). Childhood and adolescent depression: a review of the past 10 years. Part I. Journal of American Academy of Child and Adolescent Psychiatry, 35(11), 1427-1439.

[2] Kessler, R. C., Avenevoli, S., \& Ries Merikangas, K. R. (2001). Mood disorders in children and adolescents: an epidemiologic perspective, Biological Psychiatry, 49(12), 1002-1014.

[3] Avenevoli, S., Knight, E., Kessler, R. C., Merikangas, K. R. (2008). Epidemiology of Depression in children and Adolescents. In H. R. Z. Abela \& B. L. Hankin (Eds.), Handbook of Depression in children and adolescents (pp.6-32). New York: The Guildford Press.

[4] Lannie, A., \& McCurdy, B. L. (2007). Preventing disruptive behavior in the urban classroom: Effects of the good behavior game on student and teacher behavior. Education and Treatment of children, 30(1), 85-98.

[5] Weiss, B., \& Garber, J. (2003). Developmental differences in the phenomenology of depression. Developmental Psychopathology, 15, 403-430.

[6] American Psychiatric Association. (2000). Diagnostic and statistical manual of mental disorders, (4th ed., text revision). Washington, DC: American Psychiatric Association. 
[7] Carlson, G. A., \& Kashani, J. H. (1988). Phenomenology of Major Depression from childhood through adulthood: Analysis of three studies. American Journal of Psychiatry, 145(10).

[8] Cicchetti, D., \& Toth, S. L. (1998). The development of depression in children and adolescents. American Psychologist, 53, 221-241.

[9] Conrad, M., \& Hammen, C. (1993). Protective and resilience factors in high and low risk children: A comparison of children of unipolar, bipolar, medically ill and normal mothers. Development and Psychopathology, 5, 593-607.

[10] Cheung, S. K. (1995). Life events, classroom environment, achievement expectation and depression among early adolescents. Social Behavior and Personality: An International Journal, 23, 83-92.

[11] Herman-Stahl, M., \& Petersen, A. C. (1996). The protective role $\mathrm{f}$ coping and social resources for depressive symptoms among young adolescents. Journal of Youth and Adolescence, 25 (6), $733-753$.

[12] Algozzine, B., Wang, C., \& Violette, A. S. (2011). Reexamining the relationship between academic achievement and social behavior. Journal of Positive Behavioral difficulties, 13, 3-16.

[13] Huberty, T. (2010). Depression: Supporting students at school. From Helping children at home and school III: Handouts for families and Educators. National Association of School Psychologists.

[14] Widmark, C., Sandahl, Ch., Piuva, K., \& Bergman, D. (2011). Barriers to Collaboration between Health Care, Social Services and Schools. International Journal of Integrated Care, $11,1-9$.

[15] Desrochers, J. E., \& Houck, G. M. (2013). Depression in children and adolescents: Guidelines for school practice: Handout C. National Association of School Nurses. National Association of School Psychologists.

[16] Kidger, J., Araya, R., Donovan, J., \& Gunnell, D. (2012). The effect of the school environment on the emotional health of adolescents: A systematic review, Pediatrics, 192 (5), 925949.

[17] Lester, L., \& Cross, D. (2015). The relationship between school climate and mental and emotional wellbeing over the transition from primary to secondary school. Psychological Wellbeing, 5(1), 9 .

[18] Fazel, M., Hoagwood, K., Stephan, S., Ford, T. (2014). Mental health interventions in schools in high-income countries. Lancet Psychiatry, 1(5), 377-387.

[19] Durlak, J. A., Weissberg, R. P., Dymnicki, A. B., Taylor, R. D., \& Schellinger, K. B. (2011). The impact of enhancing students' social and emotional learning: A meta-analysis of school-based universal interventions. Child Development, 82(1), 405-432.

[20] Merrell, K. W., Gueldner, B. A., Ross, S. W., \& Isava, D. M. (2008). How effective are school bullying intervention program ? A meta-analysis of intervention research. School Psychology Quarterly, 23, 26-42.

[21] Gillham, J. E., Shatte, A. J., \& Freres, D. R. (2000). Depression prevention: A review of cognitive-behavioral and family interventions. Applied and Preventive Psychology, 9, 63-88.

[22] Christensen, H., Calear,, A., Tait, R., Gosling, J., Griffiths, K., $\&$ Murray, K. (2011). School based intervention programs and shared care collaborative models targeting the prevention of or early intervention in child and adolescent mental health problems: an Evidence check rapid review brokered by the Sax Institute. http://www.saxinstitute.org.au/for the NSW Ministry of Health.

[23] Brunwasser, S. M., Gillham, J. E., \& Kim, E. S. (2009). A meta-analytic review of the Penn Resiliency Program's effect on depressive symptoms. Journal of Consulting and Clinical Psychology.

[24] Gillham, J. E., Brunwasser, S. M., Freres, D. R. (2008). Preventing depression in early adolescence: The Penn Resiliency Program, In Abela J. R. Z. Hankin, B. L. (eds.), Handbook of depression in children and adolescents. New York, N. Y: Guildford Press, 309-332.

[25] Schultz, J. L., \& Mueller, D. (2007). Effective Interventions for the prevention and treatment of depression and adolescent girls: A review of relevant research. Saint Paul, MN: Wilder Research.

[26] Beardslee, W. R., Salt, P., Versage, E. M., Gladstone, T. R. G., Wright, E. J., \& Rothberg, P. C. (1997). Sustained change in parents receiving preventive interventions for families with depression. American Journal of Psychiatry, 154, 510-515.

[27] Calear, A. Z., \& Christensen, H. (2010). Systematic review of school based prevention and early intervention programs for depression. Journal of Adolescence, 33, 429-438.

[28] Poulou, M., \& Norwich, B. (2000). Teachers' causal attributions, cognitive, emotional, and behavioural responses to students with emotional and behavioral difficulties. British Journal of Educational Psychology, 70, 559-581.

[29] Vostanis, P., Humphrey, N., Fitzgerald, N., Deighton, J., \& Wolpert, M. (2013). How do schools promote emotional wellbeing among their pupils ? Findings from a national scoping survey of mental health provision in English schools. Child and Adolescent Mental Health, 18(3), 151-157.

[30] Stefan, C. A., Rebega, O. L., \& Cosma, A. (2014). Romanian preschool teachers understanding of emotional and behavioural difficulties: Implications for designing teacher training. Journal of Early Childhood Teacher Education, 36(1), 61-83.

[31] Kusche, C. A., \& Greenberg, M. T. (2006). Brain Development and socio-emotional learning: An introduction for educators. In M. J. Elias \& H. Arnold (Eds.), The educator's guide to emotional intelligence and academic achievement. Thousand Oaks, CA: Corwin Press.

[32] Bowman, B., Donovan, M., \& Burns, M. (2001). Eager to learn: Educating our preschoolers. Washington, DC: National Academy Press.

[33] Merrell, K. W. (2010). Linking prevention science and social emotional learning: The Oregon Resiliency Project. Psychology in the Schools, 47, 55-68.

[34] Rimm-Kaufman, S. E., \& Hamre, B. K. (2010). The role of psychological and developmental science in efforts to improve teacher quality. Teachers College Record, 112 (12), 2988-3023. 
[35] Daniel, J. (2009). Intentionally thoughtful family engagement in early childhood education. Young Children, 64(5), 10-14.

[36] Reinke, W. M., Stormont, M., Herman, K. C., Puri, R., \& Goel, N. (2011). Supporting children's mental health in schools: Teacher perceptions of needs, roles and barriers. School Psychology Quarterly, 26(1), 1-13.
[37] Shepherd, J., Dewhirst, S., Pickett, K., Byrne, J., Speller, V., Grace, M., Almond, P., Hartwell, D., and Roderick, P. (2013). Factors facilitating and constraining the delivery of effective teacher training to promote health and well-being in schools: a survey of current practice and systematic review. Public Health Res, 1 (2): 1-187. 